\title{
Conhecimento, Opinião e Conduta de Ginecologistas e Obstetras Brasileiros sobre o Aborto Induzido
}

\author{
Knowledge, Opinion and Attitudes of Brazilian Gynecologists and
} Obstetricians regarding Induction of Abortion

Aníbal Faúndes ${ }^{1,2}$, Graciana Alves Duarte ${ }^{1}$, Jorge Andalaft Neto ${ }^{3}$, Adriane Elisabeth Olivatto ${ }^{1}$, Rosana Martins Simoneti ${ }^{4}$

\begin{abstract}
RESUM0
Objetivo: avaliar conhecimento, opinião e conduta de ginecologistas e obstetras sobre o aborto induzido.

Método: questionário estruturado e pré-testado foi enviado a ginecologistas e obstetras associados a FEBRASGO. Solicitou-se preenchê-lo sem identificar-se e retorná-lo em envelope pré-selado que o acompanhava, para assegurar anonimato. Perguntou-se sobre conhecimento da legalidade do aborto no Brasil, opinião sobre a mesma e conduta em situações de solicitação de aborto.
\end{abstract}

Resultados: para 90\% o aborto é legal nos casos de gravidez por estupro e risco de vida para a gestante, e para 31,8\% quando existe malformação congênita grave. Opinaram que o aborto deveria ser permitido quando há risco de vida da gestante (79,3\%), malformação fetal (77,0\%) e quando a gravidez for resultado de estupro (76,6\%), e 9,9\% opinaram que deveria permitirse em qualquer circunstância. Dois terços acreditavam que se precisa de alvará judicial para realizar aborto previsto em lei, e 27,4\% sabiam que se requer solicitação da mulher. Diante da gravidez indesejada, 77,6\% das mulheres ginecologistas/obstetras e 79,9\% das parceiras dos ginecologistas/obstetras que a experimentaram referiram que foi feito um aborto; $40 \%$ ajudariam uma paciente e 48,5\% a uma familiar na mesma situação.

Conclusão: falta conhecimento da situação legal do aborto entre os ginecologistas e obstetras, apesar de grande maioria ter atitudes e condutas favoráveis.

PALAVRAS-CHAVE: Aborto previsto em lei. Aborto ilegal. Mortalidade materna. Malformações fetais.

${ }^{1}$ Centro de Pesquisas Materno-Infantis de Campinas Cemicamp; ${ }^{2}$ Departamento de Tocoginecologia, Faculdade de Medicina, Universidade Estadual de Campinas; ${ }^{3}$ Comissão Nacional Especializada de Violência Sexual e Aborto Previsto por Lei, da FEBRASGO; ${ }^{4}$ Centro de Ciências Médicas e Biológicas - Pontifícia Universidade Católica (PUC) de São Paulo

Pesquisa realizada no Centro de Pesquisas Materno-Infantis de Campinas - Cemicamp

Correspondência:

Aníbal Faúndes

Caixa Postal 6181

13084-971 - Campinas - SP

Telefone: (19) 3289-2856 / Fax: (19) 3289-2440

e-mail: afaundes@unicamp.br

Pesquisa parcialmente financiada por: Fundação de Amparo à Pesquisa do Estado de São Paulo - FAPESP; Fundo de Apoio Ao Ensino e Pesquisa - FAEP - da Fundação para o Desenvolvimento da UNICAMP (FUNCAMP) e Ipas, North Carolina, USA
Introdução

O aborto provocado é reconhecido como importante problema de saúde pública em todo o mundo, principalmente nos países com leis que restringem a sua prática. A taxa de aborto por 1000 mulheres em idade fértil varia amplamente entre 4/1000 em países como a Holanda e mais de 60 ou 80/1000 em países do Leste Europeu ${ }^{1,2}$. O Brasil encontra-se entre estes extremos, com taxa 10 vezes superior à da Holanda, mas inferior à observada nos ex-países socialistas da Europa Oriental $^{3}$. A maioria das pessoas gostaria que nenhuma mulher tivesse que provocar um aborto, e mesmo muitas mulheres que terminam fazendo 
a interrupção de sua gravidez expressavam opinião contrária a essa prática até terem-se visto na situação que as levou a essa conduta ${ }^{4}$. O fato é que, apesar das proibições legais e religiosas, o aborto continua existindo e constitui causa de 10 a 15\% dos óbitos maternos no Brasil ${ }^{5,6}$.

O Código Penal brasileiro não prevê punição para o aborto praticado por médico quando a gravidez é resultado de estupro ou se não há outro meio de salvar a vida da mulher ${ }^{7}$. Todos os demais casos são passiveis de punição, com penas que variam de um a dez anos de prisão para a mulher e para a pessoa que realiza o aborto, sendo que, para esta última, a pena pode dobrar

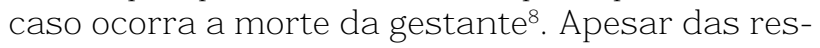
trições legais existentes no Brasil, Oliveira ${ }^{9}$ apontou que, de cada mil mulheres em idade fértil, 18 já haviam sofrido seqüelas de aborto e, de cada quatro que haviam se submetido a um aborto clandestino, uma já havia sido internada com complicações que levaram à esterilidade, ou até mesmo à morte.

Considerando que a violência sexual é fenômeno de alta prevalência ${ }^{10-14}$, e que cerca de $30 \%$ das mortes maternas resultam de complicações de doenças que já existiam antes da gravidez ${ }^{15}$, muitas mulheres cumpririam as condições para interrupção da gestação dentro da lei. Entretanto, a prática do aborto previsto na lei em hospitais públicos é absoluta exceção. Isto significa que grande contingente de mulheres, que deveria ter acesso ao aborto com segurança em ambiente hospitalar, coloca sua vida em risco por submeter-se a abortos clandestinos.

Isto motivou o Centro de Pesquisas Materno-Infantis de Campinas (Cemicamp) a estudar, em 1996, os procedimentos seguidos pelos poucos hospitais que tinham realizado abortos previstos na lei até então. A partir desse estudo, foi convocado o Primeiro Fórum Interprofissional sobre implementação do aborto previsto na lei, em novembro de 1996, com participação de professores universitários, grupos de mulheres e representantes do poder judiciário ${ }^{16}$. O objetivo do Fórum foi definir os procedimentos que deveriam ser adotados nos hospitais para realizar este tipo de aborto e estimular a implantação desses serviços, principalmente em hospitais universitários.

Em 1997, a Federação Brasileira de Sociedades de Ginecologia e Obstetrícia (FEBRASGO) criou o Comitê Nacional especializado sobre violência sexual e aborto previsto em lei, e logo, em 1998, o Ministério da Saúde editou uma portaria específica sobre esse assunto ${ }^{17}$. Até a pre- sente data, porém, não se conhecem estudos que tenham investigado de forma ampla o conhecimento, a prática e a opinião dos obstetras e ginecologistas brasileiros acerca do aborto previsto na lei, o que motivou este estudo, organizado conjuntamente pelo Cemicamp e pelo Comitê da FEBRASGO de violência sexual e aborto previsto na lei.

\section{Pacientes e Métodos}

Foi realizado estudo do tipo inquérito CAP conhecimento, atitude e prática. Para obter as informações utilizou-se um questionário estruturado, para ser auto-respondido, que foi pré-testado com médicos ginecologistas e obstetras. Esse questionário continha somente perguntas com respostas pré-codificadas, em que deveriam ser assinaladas as alternativas que os participantes julgassem pertinentes.

O conhecimento sobre a lei referente ao aborto no Brasil foi investigado por meio das seguintes perguntas: 1) em que circunstâncias a lei brasileira não pune o aborto? Oferecendo nove alternativas, dentre as quais incluiam-se as duas situações em que o aborto não é penalizado; 2) quais documentos devem ser apresentados pela mulher para obtenção do aborto previsto na lei? 3) quais documentos são necessários em caso de malformação fetal grave? Para estas duas últimas perguntas foram oferecidas as mesmas alternativas de resposta, incluindo documentos que não são requeridos e aqueles que efetivamente devem ser exigidos, segundo a norma do Ministério da Saúde sobre o assunto ${ }^{17}$.

A opinião sobre o aborto foi avaliada perguntando-se: 1) em que circunstâncias o aborto deveria ser permitido? Sendo apresentada a mesma lista de alternativas utilizadas na pergunta sobre conhecimento da lei; 2) que mudanças faria à lei? Com as seguintes alternativas: a lei não deveria ser modificada, o aborto não deveria ser considerado crime, em qualquer circunstância; as circunstâncias em que é permitido deveriam ser ampliadas; ou deveria ser sempre proibido; as restrições deveriam ser ampliadas. Por último, referente ao aborto em caso de risco para a vida da gestante, perguntou-se quanto maior que o "normal" deveria ser esse risco para que se justificasse o aborto, dando como alternativas: risco 2, 5, 10,20 e 50 vezes maior que o "normal".

Quanto à prática, investigou-se qual era a conduta do profissional em caso de uma cliente já 
conhecida pedir sua ajuda diante de gravidez absolutamente não desejada, oferecendo-se as seguintes alternativas: faz o aborto, ensina a usar misoprostol, encaminha para médico de confiança ou pede para consultar outro médico. A mesma pergunta foi repetida para o caso de uma pessoa da família, próxima, consultar com o mesmo problema. Por último, foi perguntado se alguma vez as respondentes de sexo feminino, ou a parceira dos respondentes de sexo masculino, tiveram uma gravidez absolutamente não desejada, e, em caso positivo, se praticou o aborto ou permitiu continuar a gravidez.

Para identificar os médicos que deveriam receber o questionário, primeiramente foi feito um levantamento junto à FEBRASGO, que indicou a existência de 14.320 ginecologistas e obstetras associados. O questionário da pesquisa foi enviado a cada um desses profissionais, acompanhado de: 1) uma carta convite, por meio da qual os participantes receberam informações sobre a pesquisa e sobre a maneira de preencher o questionário e enviá-lo de volta; 2) um cupom para sorteio e 3) um envelope carta-resposta para envio do questionário preenchido. Esse material foi enviado à empresa responsável pela distribuição do Jornal da FEBRASGO e os envelopes foram encaminhados aos médicos juntamente com o Jornal, Ano $9 \mathrm{~N}^{\circ} 10$ - nov/dez - 2002, ao final do mês de janeiro de 2003. Um mês após os associados terem recebido o convite para participar da pesquisa, o questionário foi novamente enviado aos 14.320 associados, pelo Jornal da FEBRASGO, Ano $10 \mathrm{~N}^{\circ} 1-\mathrm{jan} / \mathrm{fev}-2003$, ao final do mês de fevereiro de 2003. Na carta que acompanhou o questionário tornava-se a pedir aos médicos que o respondessem, se ainda não o tivessem feito, visando a estimular sua participação no estudo. Foi necessário enviar novamente o convite a todos os médicos porque não era possivel identificar apenas os que não haviam respondido, dadas às medidas adotadas para assegurar o anonimato.

Entre 10 de fevereiro e 23 de junho de 2003 foram recebidas 4.294 cartas-resposta, sendo que nove médicos devolveram o questionário totalmente em branco. Os questionários preenchidos foram numerados, revisados e arquivados à medida que chegavam. Os dados foram digitados duas vezes, por pessoas distintas, diretamente a partir dos questionários, para que fosse feita a consistência da digitação. Para todos os procedimentos de digitação, checagem e análise dos dados, foi utilizado o módulo de entrada de dados do Statistical Package for Social Sciences - SPSS PC-DE ${ }^{18}$.

A participação dos ginecologistas e obstetras neste estudo foi voluntária e anônima. Uma vez que a pesquisa abordou um assunto polêmico e com implicações legais, não foi pedido aos médicos que assinassem um Termo de Consentimento Livre e Esclarecido, com o objetivo de que não houvesse qualquer informação que pudesse identificar quem respondeu o questionário. A carta convite continha esclarecimentos sobre a pesquisa e todas as informações pertinentes exigidas pela Resolução 196/96 do Conselho Nacional de Saúde do Ministério da Saúde ${ }^{19}$. Foi considerado que o fato de responderem às perguntas e enviarem de volta o questionário constituiria o consentimento em participar da pesquisa. O sigilo quanto à fonte das informações foi assegurado ao se identificarem os questionários apenas por um número, que lhes foi atribuído ao serem devolvidos. O protocolo de pesquisa foi avaliado e aprovado pelo Comitê de Ética em Pesquisa da Faculdade de Ciências Médicas da Universidade Estadual de Campinas.

\section{Resultados}

\section{Caracteristicas dos médicos que responderam}

Um terço dos médicos tinha até 39 anos de idade, pouco mais de um terço $(34,4 \%)$ entre 40 e 49 anos e pouco menos de um terço $(31,9 \%) 50$ anos ou mais. Houve ligeiro predomínio do sexo masculino $(54,1 \%)$ sobre o feminino $(45,9 \%)$. Quase $60 \%$ moravam na Região Sudeste, menos de $20 \%$ no Sul, menos de $15 \%$ no Nordeste e percentagens menores no Centro-Oeste e no Nordeste (Tabela 1).

Quase $80 \%$ estavam em união estável, a maioria estava casada $(73,4 \%), 8,3 \%$ tinham sido casados alguma vez e $12,1 \%$ eram solteiros. A metade dos médicos que responderam tinha um ou dois filhos (50,9\%), $27 \%$ tinham três ou mais e $22,1 \%$ não tinham filhos. Quase $30 \%$ dos médicos que responderam afirmaram que sua religião havia sido muito importante para as respostas dadas ao questionário, e a maior parte considerava que sua religião não aceitava o aborto em nenhuma circunstância (Tabela 1).

Menos de $8 \%$ dos médicos trabalhavam somente no setor público e uma quarta parte só no setor privado. Os médicos se dividiram em partes quase iguais entre os que trabalhavam na capital e no interior de seus estados, sendo que quase $8 \%$ referiram ambos lugares. Pouco mais da metade tinha entre mais de 10 e 25 anos de atuação na área de gineco-obstetrícia (Tabela 1). 
Tabela 1 - Distribuição dos participantes segundo influência da religião, região e características de trabalho.

\begin{tabular}{|c|c|c|}
\hline Características & $\mathrm{n}$ & $\%$ \\
\hline \multicolumn{3}{|c|}{ Importância da religião sobre as respostas dadas ${ }^{+}$} \\
\hline Muito importante & 1193 & 28,6 \\
\hline Pouco importante & 1087 & 26,0 \\
\hline Não importante & 1454 & 34,8 \\
\hline Sem religião & 441 & 10,6 \\
\hline \multicolumn{3}{|l|}{ Religião aceita aborto\# } \\
\hline Sim, em qualquer situação & 5 & 0,1 \\
\hline Sim, em algumas situações & 415 & 11,1 \\
\hline Em nenhuma situação & 3159 & 84,5 \\
\hline Não sabe & 161 & 4,3 \\
\hline \multicolumn{3}{|l|}{ Região de moradia } \\
\hline Norte & 121 & 2,8 \\
\hline Nordeste & 579 & 13,6 \\
\hline Centro-oeste & 267 & 6,3 \\
\hline Sudeste & 2495 & 58,7 \\
\hline Sul & 789 & 18,6 \\
\hline Total $^{*}$ & 4261 & \\
\hline \multicolumn{3}{|l|}{ Tipo do serviço onde atua } \\
\hline Público & 314 & 7,6 \\
\hline Privado & 1023 & 24,7 \\
\hline Público e privado & 2790 & 67,5 \\
\hline Aposentado & 7 & 0,2 \\
\hline \multicolumn{3}{|l|}{ Localidade onde trabalha } \\
\hline Capital & 1982 & 47,0 \\
\hline Interior & 1907 & 45,2 \\
\hline Capital e interior & 324 & 7,6 \\
\hline Aposentado & 7 & 0,2 \\
\hline \multicolumn{3}{|c|}{ Tempo de atuação na área (em anos) } \\
\hline Até 10 & 1087 & 26,0 \\
\hline Mais de 10 até 25 & 2171 & 51,9 \\
\hline Mais de 25 & 924 & 22,1 \\
\hline Total ${ }^{@}$ & 4261 & \\
\hline
\end{tabular}

"Faltaram informações sobre idade (45), sexo (24), estado marital (27), importância da religião (79), religião aceita aborto (78), número de filhos vivos (20) e região de moradia (10).

+ Um médico não soube definir e 6 deram outras respostas

\#Dois médicos deram outras respostas e 441 não tinham religião.

@ Faltou informação sobre tipo de serviço (127), localidade de trabalho (41) e tempo de atuação na área (79).

\section{Conhecimento sobre a lei referente a aborto}

Quase 93\% dos médicos que responderam sabiam corretamente que a lei brasileira não pune o aborto se a gravidez é resultado de estupro, e quase 90\% citaram caso de risco de vida para a gestante. Quase um terço acreditava, incorretamente, que a lei também excluía de pena o aborto nos casos em que o feto tem malformações graves. Menos de $1 \%$ acreditava que a lei eximia de pena em qualquer outro dos casos propostos (Tabela 2).
Tabela 2 - Conhecimento sobre as circunstâncias nas quais a lei brasileira não pune 0 aborto praticado por médico e opinião sobre as circunstâncias nas quais 0 aborto deveria ser permitido (em percentagem).

\begin{tabular}{|c|c|c|c|c|}
\hline \multirow[b]{2}{*}{ Circunstâncias } & \multicolumn{2}{|c|}{ Conhecimento } & \multicolumn{2}{|c|}{ Opinião } \\
\hline & $\mathrm{n}$ & $\%$ & $\mathrm{n}$ & $\%$ \\
\hline $\begin{array}{l}\text { Gravidez resultante } \\
\text { de estupro }\end{array}$ & 3928 & 92,8 & 3217 & 76,6 \\
\hline $\begin{array}{l}\text { Em caso de risco de vida } \\
\text { da gestante }\end{array}$ & 3781 & 89,3 & 3330 & 79,3 \\
\hline $\begin{array}{l}\text { Feto com malformação } \\
\text { congênita grave }\end{array}$ & 1346 & 31,8 & 3233 & 77,0 \\
\hline Mãe ou parceiro HIV positivo & 20 & 0,5 & 532 & 12,7 \\
\hline $\begin{array}{l}\text { Mulher sem condições } \\
\text { psicológicas/emocionais } \\
\text { de ter o bebê }\end{array}$ & 19 & 0,4 & 731 & 17,4 \\
\hline $\begin{array}{l}\text { Mulher solteira e parceiro } \\
\text { não assume gravidez }\end{array}$ & 10 & 0,2 & 90 & 2,1 \\
\hline Falha do MAC em uso & 5 & 0,1 & 172 & 4,1 \\
\hline $\begin{array}{l}\text { Mulher não tem condições } \\
\text { financeiras de ter o bebê }\end{array}$ & 6 & 0,1 & 268 & 6,4 \\
\hline Em qualquer circunstância & & & 415 & 9,9 \\
\hline Em nenhuma circunstância & & & 190 & 4,5 \\
\hline Outro & & & 20 & 0,5 \\
\hline Total $^{*}$ & 4233 & & 4200 & \\
\hline
\end{tabular}

*Faltou informação sobre conhecimento de 28 médicos e sobre opinião de 61 médicos. MAC - método anticoncepcional.

Dois terços dos médicos acreditavam erradamente que era necessário alvará judicial para praticar aborto previsto na lei, e quase $80 \%$ referiram corretamente que este era necessário em caso de malformação congênita grave, não previsto na lei (Tabela 3). A necessidade de laudo de três médicos foi apontado corretamente por quase a metade dos respondentes para os casos previstos em lei (pensando nos casos em que há risco de vida para a gestante), por $44 \%$ em caso de malformação fetal grave, e $42 \%$ responderam acertadamente que o boletim de ocorrência era necessário (pensando em gravidez resultante de estupro). Apenas pouco mais de $25 \%$ sabia que em ambos os casos previstos na lei se necessita de solicitação por escrito da mulher, e em torno de $20 \%$ sabiam do requisito de autorização do representante legal em caso de menores (Tabela 3).

Opinião dos médicos sobre as circunstâncias em que a lei deveria permitir o aborto

A Tabela 2, além do conhecimento sobre a lei, descreve as respostas sobre o que os médicos pensavam que a lei deveria permitir. Apenas duas alternativas de resposta excluem qualquer outra: o aborto deve ser permitido "em qualquer circunstância" ou "em nenhuma circunstância". 
Tabela 3 - Opinião acerca dos documentos a serem apresentados pela mulher para obtenção do aborto nos casos previstos em lei e no caso de malformação fetal grave (em percentagem).

\begin{tabular}{|c|c|c|c|c|}
\hline \multirow[b]{2}{*}{ Documentos } & \multicolumn{2}{|c|}{ Previstos em lei } & \multicolumn{2}{|c|}{ Malformação fetal grave } \\
\hline & $\mathbf{n}$ & $\%$ & $\mathbf{n}$ & $\%$ \\
\hline Alvará judicial & 2799 & 66,2 & 3335 & 79,2 \\
\hline Laudo de três médicos & 2002 & 47,3 & 1863 & 44,2 \\
\hline Boletim de Ocorrência & 1778 & 42,0 & & \\
\hline Laudo do Instituto Médico legal & 1188 & 28,1 & & \\
\hline Solicitação por escrito, de próprio punho e assinada & 1157 & 27,4 & 1196 & 28,4 \\
\hline $\begin{array}{l}\text { Autorização por escrito do pai/responsável, caso a mulher tenha } \\
\text { menos de } 21 \text { anos }\end{array}$ & 947 & 22,4 & 818 & 19,4 \\
\hline Não sabe & 258 & 6,1 & 327 & 7,8 \\
\hline Nada & 57 & 1,3 & 103 & 2,4 \\
\hline Nada porque não é atendido; ilegal & & & 11 & 0,3 \\
\hline Total $^{*}$ & 4229 & & 4212 & \\
\hline
\end{tabular}

*Faltou informação de 32 médicos para os casos previsto em lei e de 49 para o caso de malformação fetal grave.

A situação em que a maior parte dos respondentes opinou que a lei deveria permitir o aborto foi o caso em que a gravidez representa risco de vida para a gestante, com quase $80 \%$, seguido por malformacão fetal grave e gravidez resultante de estupro, em porcentagens muito parecidas, em torno de $77 \%$. Se agregamos os quase $10 \%$ que responderam somente a alternativa "em qualquer circunstância”, temos que quase 90\% opinaram que o aborto deve ser permitido em caso de risco de vida, e em torno de $87 \%$ em caso de malformação fetal grave ou estupro (Tabela 2).

Porcentagem muito menor dos médicos que responderam se mostraram favoráveis a que o aborto seja permitido em outras circunstancias: menos de $20 \%$ para "sem condições psicológicas/emocionais", pouco mais de $10 \%$ para "mulher ou parceiro HIV+" e percentagens mínimas para outras causas. Menos de 5\% dos médicos opinaram que o aborto não deveria ser permitido "em nenhuma circunstância" (Tabela 3).

Cerca de $60 \%$ dos médicos que responderam opinaram que um aumento de 2 a 5 vezes no risco de morrer durante a gestação era suficiente para justificar o aborto, e quase $80 \%$ o justificariam mediante um risco 20 vezes ou menos acima do risco "normal" de qualquer gravidez. Perto de um de cada oito dos médicos opinou que o aborto por risco de vida para a gestante "nunca se justifica" (Tabela 4).

Quando perguntados sobre possiveis mudanças na lei brasileira referente ao aborto, quase dois terços dos médicos responderam que as circunstâncias em que o aborto não é punido deveriam ser ampliadas, e mais $15 \%$ opinaram que o aborto de- veria deixar de ser considerado um crime em qualquer circunstância. Menos de 15\% opinaram que a lei não deveria ser mudada (Tabela 5).

\begin{tabular}{lcr}
\multicolumn{4}{l}{ Tabela 4 - Opinião sobre a letalidade da doença durante a gestação que justifica a } \\
interrupção da gestação por risco de vida materno (em percentagem). \\
\hline Interrupção justifica se o risco é: & $\mathbf{n}$ & $\%$ \\
\hline 2 vezes > que normal & 1329 & 36,9 \\
5 vezes > que normal & 857 & 23,8 \\
10 vezes > que normal & 578 & 16,1 \\
20 vezes > que normal & 90 & 2,5 \\
50 vezes > que normal & 248 & 6,9 \\
Nunca se justifica & 442 & 12,3 \\
Sem opinião formada & 54 & 1,5 \\
Total & 3598 & \\
\hline
\end{tabular}

*Faltou informação de 613 médicos e 50 deram outras respostas.

Tabela 5 - Distribuição percentual de entrevistados segundo opinião acerca de uma possível mudança nas leis brasileiras sobre aborto.

\begin{tabular}{lcc}
\hline As leis brasileiras & $\mathbf{n}$ & $\%$ \\
\hline $\begin{array}{l}\text { Deveriam deixar de considerar 0 aborto como } \\
\text { crime em qualquer circunstância }\end{array}$ & 598 & 14,6 \\
$\begin{array}{l}\text { Deveriam ampliar as circunstâncias em que 0 } \\
\text { aborto não é punido }\end{array}$ & 2690 & 65,4 \\
$\quad$ Não deveriam ser modificadas & 550 & 13,4 \\
$\begin{array}{l}\text { Deveriam proibir 0 aborto e/ou ampliar as } \\
\text { restrições }\end{array}$ & 9 & 0,2 \\
Sem opinião formada & 264 & 6,4 \\
Total* & 4111 & \\
\hline
\end{tabular}

*Faltou informação de 128 médicos e 22 deram outras respostas. 


\section{Prática quanto ao aborto não previsto em lei}

Quarenta por cento dos médicos ajudariam uma cliente que consulta por gravidez não desejada e solicita aborto, embora menos de $2 \%$ declararam que fariam o aborto. A ajuda consistiria principalmente em encaminhá-la a médico de confiança e/ou ensinar a usar misoprostol. Em caso de familiar próximo, a porcentagem sobe para quase $48 \%$, mas só pouco mais de $2 \%$ faria o aborto nessas circunstâncias. Entretanto, nos casos em que a própria mulher- médica, ou a parceira do homem-médico viu-se na situação de uma gravidez absolutamente não desejada, a porcentagem que praticou o aborto subiu para 77,6 e 79,9 , respectivamente.

\section{Discussão}

Os resultados do inquérito apresentados neste trabalho mostram uma notável deficiência dos gineco-obstetras filiados à FEBRASGO quanto ao conhecimento dos preceitos legais que regulam o aborto no Brasil, e mais ainda quanto à Norma Técnica do Ministério da Saúde sobre "Prevenção e tratamento dos agravos resultantes da violência sexual contra mulheres e adolescentes", que confirma em detalhe os requisitos que devem exigir-se para a prática do aborto em caso de gravidez resultante de estupro.

Um dos erros mais freqüentes, de quase um terço dos médicos, foi acreditar que a lei não pune o aborto em caso de malformação fetal grave, o que talvez se explique pela alta freqüência de autorizações para realizar este tipo de aborto emitidas por juizes de todo o Brasil, a ponto de esses casos passarem a ser prática mais corriqueira em alguns hospitais públicos do que as causas previstas na lei.

Outro erro importante verificado neste estudo foi julgar que é preciso alvará judicial para praticar aborto previsto na lei, o que foi declarado por nada menos que dois terços dos médicos que responderam ao questionário. Este erro conceitual é um importante obstáculo para a obtenção do aborto principalmente por mulheres estupradas, já que a obtenção desse alvará pode levar mais tempo que a própria gestação ${ }^{8}$. Igualmente surpreendente foi verificar que menos de $30 \%$ dos médicos sabiam que se requer solicitação por escrito da mulher que deseja a interrupção da gravidez, tanto nos casos previstos na lei quanto se a causa for malformação fetal grave. Mais ainda, somente cerca de $20 \%$ pareciam saber que se necessita da autorização do representante legal quando a solicitante for menor de idade. Tudo isto parece indicar que a questão do aborto previsto na lei não tem preocupado os colegas filiados à FEBRASGO, embora dependa totalmente de nós que as mulheres, que sofrem as situações em que o aborto não é punido, possam ter acesso ao mesmo em hospitais públicos e não precisem recorrer às condições sórdidas e perigosas da clandestinidade.

Por outro lado, a opinião expressada pelos médicos sobre como deveria ser a lei que regula a prática do aborto foi bem mais liberal do que a lei atual. É verdade que só $10 \%$ julgam que o aborto deveria ser permitido pela lei em qualquer circunstância, mas esses 10\%, somados aos que mencionaram condições específicas, levam a quase $90 \%$ de acordo quanto ao aborto por risco de vida, e a uma porcentagem um pouco menor de acordo quanto ao aborto quando a gravidez é resultado de estupro e/ou em caso de malformação congênita grave. Esta última causa não poderia ter sido prevista pelo Código Penal na época de sua promulgação, em 1940, quando não existiam os meios atuais de diagnóstico preciso dessas condições.

A atitude favorável à maior liberalidade da lei também aparece quando se enfocam possiveis mudanças na lei. Os 10\% que opinaram que o aborto deveria ser permitido em qualquer circunstância, em resposta à pergunta em que se colocaram diversas alternativas de circunstâncias, sobem a quase $15 \%$ quando perguntados sobre possiveis mudanças na lei. Esses 15\%, somados aos 65\% que declararam que deveriam ampliar-se as circunstâncias previstas na lei, levam a $80 \%$ de médicos que se manifestaram favoráveis à ampliação dos casos em que não deveria haver a penalização ou criminalização do aborto. Como a lei atual não inclui a malformação fetal grave, entende-se que esta é a principal causa do desejo de mudança da lei. A diferença entre os $80 \%$ a favor da maior liberalização e os $87 \%$ que se mostraram especificamente favoráveis a que o aborto fosse permitido em caso de malformação grave pode dever-se a que mais de $30 \%$ dos médicos que responderam acreditavam que a lei já permitia o aborto nesses casos.

A questão do aborto por risco para a vida da gestante mereceu uma pergunta específica e agora suscita um comentário à parte. Na prática diária, o aborto por esta causa é uma grande raridade, e há quem diga que já não existem mais condições prévias à gestação que justifiquem o aborto. Essa afirmação é contestada pela simples verificação de que uma importante proporção das mortes maternas são indiretas e, portanto, resultam de condições diagnosticáveis no início da gravidez. O que acontece é que o médico é o único juiz 
que decide quanto acima do "normal" é o risco que a mulher deve estar correndo para que se justifique a interrupção da gravidez, e, em geral, supõese que esse risco deve ser muitíssimo elevado para justificar o aborto. A própria mulher nunca é consultada sobre quanto maior risco ela está disposta a correr para ter esse filho, considerando a presença de filhos anteriores e de uma família que em muito depende dela. Daí o interesse em conhecer a opinião dos gineco-obstetras sobre o tema. Foi notável não apenas que 90\% dos respondentes são favoráveis ao aborto nesses casos, mas também que $60 \%$ o justificam com um risco 5 vezes, ou menos, o "normal", e 80\% quando esse risco é 20 vezes, ou menos, o "normal". Se considerarmos que a mortalidade materna em grandes áreas do Brasil está em torno de 60 por 100.000 nascidos vivos, ou seja 0,6/1000, um risco 20 vezes maior corresponde a uma letalidade de $(0,6 \times 20) 12 / 1000$ ou $1,2 \%$. Isto contrasta com a opinião de alguns especialistas, que julgam que esse seria um risco muito pequeno para justificar a interrupção da gravidez. Falta saber se a mulher afetada está disposta a correr esse risco ou se, considerando as diversas situações de sua vida, julga que seria melhor evitá-lo.

Os resultados referentes à prática dos médicos que responderam diante do aborto em condições não previstas na lei são muito interessantes. Menos da metade deu uma resposta que representava ajudar a uma cliente que se apresentava com gravidez absolutamente não desejada, mas a porcentagem se aproximou da metade quando se tratava de familiar próximo. Quando o problema foi pessoal, aqueles que o enfrentaram decidiram que a situação justificava a prática do aborto, que efetivamente foi realizado em $77 \%$ das mulheres que responderam e em $80 \%$ das parceiras de médicos do sexo masculino que viveram essa situação. Estes resultados ilustram muito bem como a maior parte de nós considera o aborto algo absolutamente indesejável, porém há circunstâncias em que terminamos aceitando que é o mal menor. Quanto mais próximo de nós mesmos o problema, maior é a tendência a aceitar que, nesse caso particular e muito excepcional, a interrupção da gestação termina por justificar-se, sem que isto signifique que mudemos nossa rejeição natural ao aborto em si.

Entendemos que estes resultados não podem ser generalizados a todos os gineco-obstetras filiados à FEBRASGO, já que a taxa de resposta foi de aproximadamente 30\%. Podemos considerar esta taxa como satisfatória, considerando a via indireta de aproximação aos colegas e as dificuldades que sempre se têm para obter resposta a questionários enviados pelo correio. De fato, a taxa de resposta deve ser bastante mais elevada, já que não sabemos quantos médicos não receberam o Jornal da FEBRASGO e, portanto, também não receberam o questionário, ou ainda, que receberam o Jornal mas não tiveram tempo de examiná-lo e verificar que havia um envelope no seu interior.

De qualquer forma, é impossivel saber se houve algum viés de seleção, no sentido de que tenham respondido em maior proporção aqueles com idéias mais liberais ou mais restritivas referentes ao aborto. O elevado número de respostas, entretanto, sugere que dificilmente as principais conclusões, que surgem da análise acima, possam mudar de maneira significativa com maior proporção de respostas. Esperamos poder repetir o envio do questionário no próximo ano, na esperança de que a publicação destes resultados sirva de estímulo para que maior número de colegas o respondam. Agradecemos enormemente a todos aqueles que deram de seu tempo e trabalho para responder desta vez. O melhor conhecimento do que os médicos sabem, opinam e praticam no que se refere ao aborto irá ajudar a encontrar soluções racionais para este importante problema que afeta elevadíssima proporção das mulheres em algum momento de suas vidas.

\section{ABSTRACT}

Purpose: to evaluate knowledge, opinion and practice of gynecologists/obstetricians regarding induction of abortion. Method: a pretested, structured questionnaire was sent to gynecologists/obstetricians affiliated to FEBRASGO. They were asked to answer and return the questionnaire in a selfaddressed, prepaid envelope, without identification of the respondent so as to preserve anonymity. Knowledge about the legal situation of abortion in Brazil, opinion about it and practice if confronted with abortion requests were questioned.

Results: approximately 90\% of the respondents believed that abortion is legal for pregnancy resulting from rape or in case of risk to a woman's life and for $31.8 \%$ in case of severe fetal malformation. In their opinion abortion should be permitted in the case that pregnancy is a risk for a woman's life (79.3\%), fetal malformation (77.0\%) and after rape (76.6\%), added to $9.9 \%$ who expressed that abortion should be permitted in all circumstances. Two thirds wrongly thought that a judicial order is required to practice a legal abortion and only $27.4 \%$ knew that a written request by the woman is required. Confronted with unwanted pregnancy, $77.6 \%$ of female gynecologists/ obstetricians and $79.9 \%$ of partners of male respondents had an abortion, $40 \%$ would help a client and $48.5 \%$ a relative in the same situation. 
Conclusion: gynecologists/obstetricians lack knowledge on the legal situation of abortion although their opinion and practice are favorable.

KEYWORDS: Legal abortion. Illegal abortion. Maternal mortality. Fetal malformations.

\section{Referências}

1. Henshaw SK, Singh S, Haas T. The incidence of abortion worldwide. Int Fam Plann Persp 1999; 25 Suppl:S30-8.

2. Singh S, Wulf D. Estimated levels of induced abortion in six Latin American countries. Int Fam Plann Persp 1994; 20:4-13.

3. World Health Organization (WHO). Unsafe abortion: global and regional estimates of incidence and mortality from unsafe abortion. Geneva; 1998.

4. Bengtsson Agostino M, Wahlberg V. Interruption of pregnancy: motives, attitudes and contraceptive use. Gynecol Obstet Invest 1991; 32:139-43.

5. Cecatti JG, Alburquerque RM, Hardy E, Faundes A. Mortalidade materna em Recife: causas de óbitos maternos. Rev Bras Ginecol Obstet 1998; 20:7-11.

6. Parpinelli MA, Faundes A, Surita FGC, Pereira BG, Cecatti, JG. Mortalidade materna na cidade de Campinas, no período de 1992-a 1994. Rev Bras Ginecol Obstet 1999; 21:227-32.

7. Código penal: decreto lei $n^{\circ} 2848$ de 7 dez $1940.34^{a}$ ed. São Paulo: Saraiva; 1996.

8. Torres JHR. Aspectos legais do abortamento. Jornal da Rede Saúde [online] 1999; 18:7-9. Disponível em: http: / /www.redesaude.org.br/jornal/html/ body_jr18-aspleg.html
9. Oliveira EM. Aborto/cidadania: tecendo a democracia. Mandrágora 1994; 1:9-14.

10.Schraiber L, d'Oliveira AF, Hanada H, et al. Violência vivida: a dor que não tem nome. Interface Comum Saúde Educ 2003; 7:41-54.

11.Heise L, Ellsberg M, Gottmoeller M. A global overview of gender-based violence. Int $\mathrm{J}$ Gynaecol Obstet 2002; 78 (Suppl. 1):S5- 14.

12.Watts C, Zimmerman C. Violence against women: global scope and magnitude. Lancet 2002; 359:1232-7.

13.Polanczyk GV, Zavaschi ML, Benetti S, Zenker R, Gammerman PW. Violência sexual e sua prevalência em adolescentes de Porto Alegre, Brasil. Rev Saúde Pública 2003; 37:8-14.

14.Faúndes A, Hardy E, Osis MJ, Duarte G. O risco para queixas ginecológicas e disfunções sexuais segundo história de violência sexual. Rev Bras Ginecol Obstet 2000; 22:153-7.

15.Albuquerque RM, Cecatti JG, Hardy E, Faúndes A. Fatores sócio-demográficos e de assistência médica associados ao óbito materno. Rev Bras Ginecol Obstet 1998; 20:181-5.

16. Faúndes A, Bedone A, Pinto e Silva JL. I Fórum interprofissional para implementação do atendimento ao aborto previsto na lei. Relatório Final. Femina 1997; 25:69-78.

17.Ministério Saúde. Secretaria de Políticas de Saúde. Departamento de Gestão de Políticas Estratégicas. Prevenção e tratamento dos agravos resultantes da violência sexual contra mulheres e adolescentes. Norma Técnica. Brasília; 1999.

18.SPSS for windows. [computer program] Version 6.0. Chicago: SPSS; 1993.

19.Ministério da Saúde. Conselho Nacional de Saúde. Resolução 196/96 dispõe sobre pesquisa envolvendo seres humanos. Inf Epidemiol SUS 1996; 5 (Supl 3):13-41.

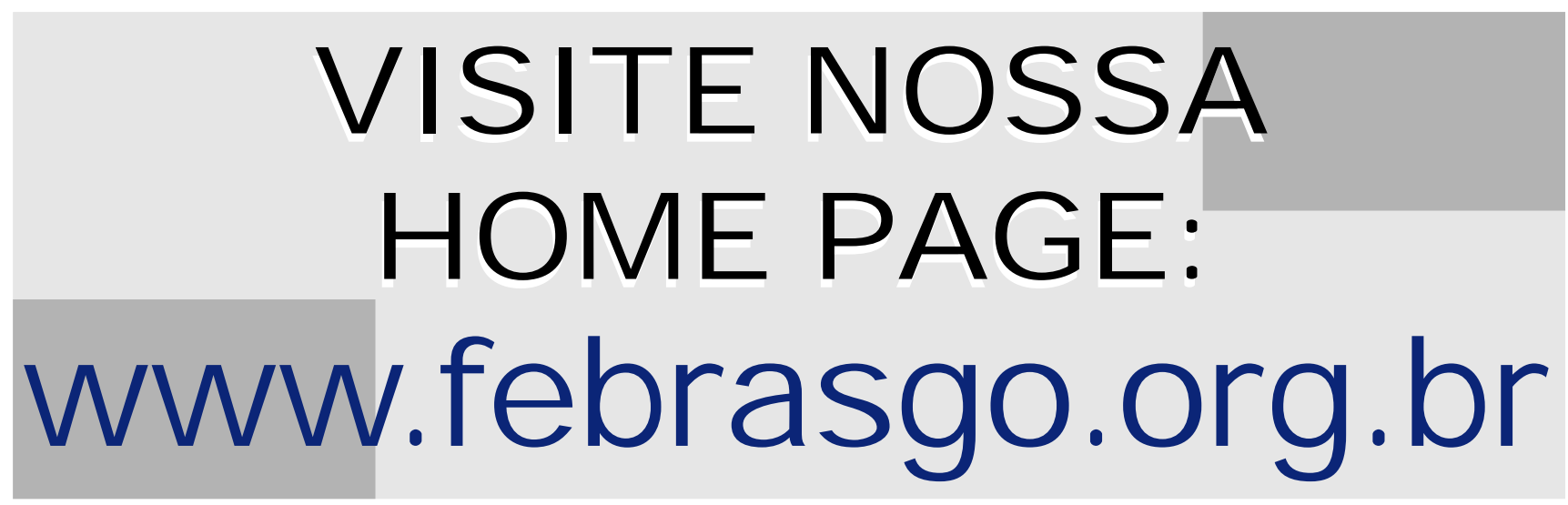

